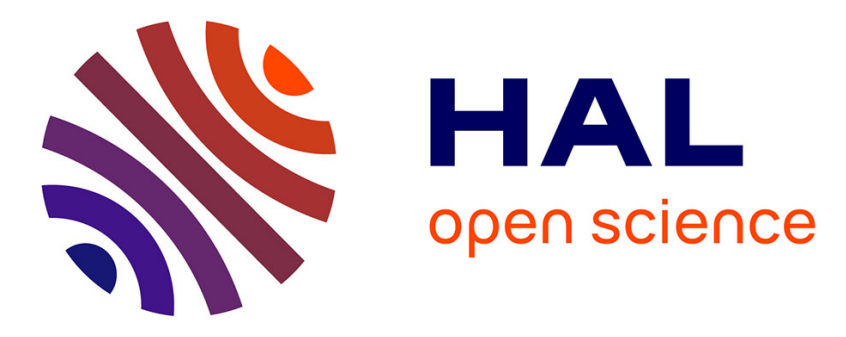

\title{
Insights into the Rheological Behavior of Aqueous Dispersions of Synthetic Saponite: Effects of Saponite Composition and Sodium Polyacrylate
}

Cunjun Li, Qiqi Wu, Sabine Petit, Will Gates, Huimin Yang, Weihua Yu, Chunhui Zhou

\section{To cite this version:}

Cunjun Li, Qiqi Wu, Sabine Petit, Will Gates, Huimin Yang, et al.. Insights into the Rheological Behavior of Aqueous Dispersions of Synthetic Saponite: Effects of Saponite Composition and Sodium Polyacrylate. Langmuir, 2019, 35 (40), pp.13040-13052. 10.1021/acs.langmuir.9b01805 . hal-02363075

\section{HAL Id: hal-02363075 \\ https://cnrs.hal.science/hal-02363075}

Submitted on 3 Dec 2020

HAL is a multi-disciplinary open access archive for the deposit and dissemination of scientific research documents, whether they are published or not. The documents may come from teaching and research institutions in France or abroad, or from public or private research centers.
L'archive ouverte pluridisciplinaire HAL, est destinée au dépôt et à la diffusion de documents scientifiques de niveau recherche, publiés ou non, émanant des établissements d'enseignement et de recherche français ou étrangers, des laboratoires publics ou privés. 
Insights into the Rheological Behavior of Aqueous Dispersions of Synthetic Saponite: Effects of Saponite Composition and Sodium Polyacrylate

\author{
Cunjun $\mathrm{Li}^{\mathrm{a}}$, Qiqi $\mathrm{Wu}^{\mathrm{a}}$, Sabine Petit ${ }^{\mathrm{e}}$, Will P. Gates ${ }^{\mathrm{f}}$, Huimin Yang ${ }^{\mathrm{d}}$, Weihua $\mathrm{Yu}^{\mathrm{ac}} \&$ Chunhui \\ Zhou ${ }^{\text {ab * }}$ \\ ${ }^{a}$ Research Group for Advanced Materials \& Sustainable Catalysis (AMSC), State Key Laboratory Breeding Base \\ of Green Chemistry-Synthesis Technology, College of Chemical Engineering, Zhejiang University of Technology, \\ ${ }^{\mathrm{b}}$ Qing Yang Institute for Industrial Minerals, You Hua, Qing Yang, Chi Zhou 242804, China \\ ${ }^{\mathrm{c}}$ Zhijiang College, Zhejiang University of Technology, Shaoxing 312030, China \\ ${ }^{\mathrm{d}}$ Key Laboratory of High Efficient Processing of Bamboo of Zhejiang Province, China National Bamboo Research \\ Center, Hangzhou, 310012, China \\ ${ }^{\mathrm{e}}$ Institut de Chimie des Milieux et Matériaux de Poitiers (IC2MP), UMR 7285 CNRS, Université de Poitiers, \\ Poitiers Cedex 9, France \\ ${ }^{\mathrm{f}}$ Institute for Frontier Materials, Deakin University Melbourne-Burwood, Burwood, Victoria 3125, Australia \\ * Prof. C.H. ZHOU, E-mail: clay @zjut.edu.cn
}

\title{
Abstract
}

Synthetic saponite (Sap) easily delaminates in water to form a transparent sol and hydrogel with excellent rheological performance and is thus widely used in paints, cosmetics, and nanomaterials. The thixotropic property of Sap hydrogels is heavily dependent on the nature of Sap and the external electrolyte and polyelectrolyte; yet, details on the relationship between rheological behaviors of saponite hydrogels and Sap composition and polyelectrolyte remain unclear. In this work, thixotropic rheological behaviors of a series of synthetic Sap hydrogels, with and without added sodium polyacrylate polyelectrolyte (NaPA), were investigated. The Sap samples, with a $\mathrm{Si} / \mathrm{Al}$ molar ratio from 5 to 25 , were successfully synthesized using hydrothermal methods and characterized by powder X-ray diffraction, Fourier transform infrared spectroscopy, and scanning electron microscopy. The rheological performances of aqueous Sap dispersions and particle sizes and $\zeta$-potentials of Sap were measured. The results showed that the crystallinity of the Sap increased with an increasing Si/Al molar ratio. All Sap samples, with the exception of the Sap with a Si/Al molar ratio of 5 , dispersed well in water $(3 \mathrm{wt} \%)$ to form hydrogels. The rheological behaviors of the hydrogels were related to the chemical composition and the layer charge of the Sap. The Sap with a Si/Al molar ratio of 25 had higher viscosity due to improved delamination. The addition of the NaPA, an anionic polyelectrolyte, into the hydrogels decreased the viscosity 
and altered the thixotropic properties such that the hydrogel becomes a sol. The addition of NaPA facilitated the dispersion and delamination of Sap, because under the electric field of negatively charged Sap particles in the hydrogel, the anionic NaPA was instantaneously polarized and thereby entered the hydration layer of the Sap particles.

\section{Introduction}

Saponite (Sap) is a 2:1 trioctahedral clay mineral. A layer of Sap is composed of two sheets of hexagonally arrayed [SiO4] tetrahedra sandwiching a central sheet of $[\mathrm{MgO}(\mathrm{OH}) 2]$ octahedra. A small amount of isomorphous substitution of $\mathrm{Si} 4+$ for $\mathrm{Al} 3+$ (and sometimes other trivalent cations such as $\mathrm{Fe} 3+$ ) in the tetrahedral sheet causes a negatively charged sheet. In many types of Sap, $\mathrm{Al} 3+$ or $\mathrm{Fe} 3+$ can substitute $\mathrm{Mg} 2+$ in the octahedral sheet, creating a positive octahedral sheet charge; however, substitution in the tetrahedral results in an overall negative net charge of the 2:1 layer.1 The negative layer charge is compensated by exchangeable cations such as $\mathrm{Na}+$, $\mathrm{NH} 4+, \mathrm{K}+, \mathrm{Li}+$, and $\mathrm{Mg} 2+$, which reside in the (generally) hydrated interlayer. An ideal structural formula of Sap is thus described as $\mathrm{Mx} / \mathrm{z} \mathrm{z}^{+}[\mathrm{Mg} 6][\mathrm{Si} 8-\mathrm{xAlx}] \mathrm{O} 20(\mathrm{OH}) 4 \cdot \mathrm{nH} 2 \mathrm{O}$, where $\mathrm{Mz}+$ represents the interlayer cations, $\mathrm{x}$ ranges from approximately $0.4-1.2$, and $\mathrm{n}$ represents the number of surface- and/or cation hydration water molecules. 2 Compared to montmorillonite, Sap generally has a smaller particle size and higher thermal stability.3 In particular, Sap can be more readily delaminated and exfoliated into nanoplatelets or even single nanolayers in water.4 As is typical of high swelling smectites, in aqueous dispersion, its solid-water interfacial properties enable it to form colloidal sols or gels. For this reason, Sap has been used for many decades as a nontoxic thickener,5 plasticizer,6 or emulsifier7 in products such as paint, plaster, cosmetics, personal care products, and adhesives.8 Naturally occurring saponite deposits are scarce and generally contain mineral and metal impurities, and hence laborious and time-consuming purification is required.9 This limitation restricts the use of natural Sap; the potential of its synthetic counterparts in industrial applications is therefore of interest. The technology of synthesizing Sap-like clay minerals with a well-controlled chemical composition has been successfully developed, and the products are generally referred to as a synthetic Sap (Sap). In the past, three successful approaches in the synthesis of Sap have been applied: microwave-assisted,10 nonhydrothermal,11,12 and hydrothermal.13,14 The microwave-assisted method is conducive to reduction of synthesis time and control of the structure with large pores and high specific surface area.15,16 To make the process rapid and feasible in industrial-scale, the 
nonhydrothermal method under mild condition was developed.12,17 Typically, a gel containing the source of $\mathrm{Si}, \mathrm{Al}$, and $\mathrm{Na}$ was first prepared at room temperature, followed by mixing it with a solution of urea and metal salts (introducing special metal cations, such as Co and $\mathrm{Ni}$ ). In this way, the octahedral sheets of saponites can be easily designed to contain one or more of different metal cations. As the hydrothermal method requires only relatively simple equipment and the reaction conditions are easy to control with precision, it is the frequently used approach for Sap synthesis.13 For many industrial applications, Sap (whether synthetic or natural) commonly needs surface engineering (functionalization), such as intercalation and/or hybridization to enhance its reactivity. Recently, various new Sap-based functional materials, such as nanoparticles/Sap hydrogels, surface-functionalized Sap, and inorganically modified and hybridized Sap, were designed to produce new functional materials. These Sapbased functional materials may exhibit exceptional biological, electrical, and optical properties and applied in electromagnetic, magnetorheological, catalytic, and biological fields.18-20 Such functionalization is usually conducted in aqueous dispersions. In addition, electrolytes are frequently added to adjust the rheological performance of the Sap-based products in practice. Therefore, understanding the physical and chemical interactions between Sap and electrolytes in an aqueous dispersion is critical and fundamental. Deep experimental and theoretical understanding of the rheological behavior of aqueous dispersions of synthetic saponite is worthwhile. Aqueous dispersions and hydrogels of Sap can exhibit different physical states, for example, stable colloidal dispersion or viscoelastic sol and elastic solids.21,22 The rheological properties of Sap hydrogels are related to electrolyte concentration.23 Shear thinning is a common phenomenon for flocs/aggregates that break down when shear is applied. However, shear thickening is uncommon for most clay dispersions and implies that energy input is dissipated into enhanced gels. Thixotropy is the hysteresis in shear stress between increasing and decreasing shear rate paths. Most clay gels undergo shear thinning with increasing shear rate but some thickening when the shear rate decreases after a prolonged exposure to a high shear rate. The Sap hydrogel system, at concentrations less than $1.1 \mathrm{wt} \%$ of solid content, displays a typical Newtonian flow, but at concentrations exceeding $1.2 \mathrm{wt} \%$, it can exhibit distinct shear thinning.24 Aspects of how the chemical composition and crystallinity of Sap affect the complex rheological behavior of Sap hydrogels remain elusive. For the purpose of tuning the shear thinning of Sap dispersions for different applications, electrolytes or polyelectrolytes can generally be introduced to help dispersion, 25 stabilization, 26 or flocculation of clay mineral suspensions.27 Sodium polyacrylate (NaPA, denoted SN-5040 in the industry) is one of the most frequently used polyelectrolytes in paints, pigments, and waste water treatment.28,29 Therefore, the thixotropy of Sap dispersion is a major factor affecting the workability of these products. However, details regarding thixotropic interactions with Sap in water have been rarely reported and rheological behaviors of aqueous Sap-NaPA dispersions are unknown. The objective of this work is to correlate the rheological 
behavior of Sap hydrogels as a function of the chemical composition of Sap and load rates of NaPA.

\section{Experimental Section}

\subsection{Synthesis of saponite}

119 The synthesis procedure was as follows: a mixture of $36.3 \mathrm{~g}$ of $\mathrm{NaOH}$ and $65.6 \mathrm{~g}$ of $\mathrm{NaHCO} 3$ was dissolved in $500 \mathrm{~mL}$ of deionized water to develop solution A. Then, $88.83 \mathrm{~g}$ of sodium silicate was added in $490 \mathrm{~mL}$ of solution A under vigorous stirring to create solution B. A given amount of $\mathrm{MgCl} 2 \cdot 6 \mathrm{H} 2 \mathrm{O}$ and $\mathrm{AlCl} 3 \cdot 6 \mathrm{H} 2 \mathrm{O}$ was dissolved in $175 \mathrm{~mL}$ of deionized water (solution $\mathrm{C}$ ) to provide a range of $\mathrm{Si} / \mathrm{Al}$ in the final product. Under continuous stirring, solution $\mathrm{C}$ was slowly added into solution B until a uniform white suspension was observed. The suspension was then transferred to a polytetrafluoroethylene-lined autoclave and heated at $200{ }^{\circ} \mathrm{C}$ for $24 \mathrm{~h}$. The solid phase was washed with deionized water to eliminate chlorides and finally dried at $90{ }^{\circ} \mathrm{C}$ in an oven and ground in a mortar. The obtained product was denoted Sapx, where $\mathrm{x}$ represents the $\mathrm{Si} / \mathrm{Al}$ molar ratio. For example, Sap5 means the Sap synthesized at the Si/Al molar ratio of 5.

\subsection{Preparation of Sap Hydrogels and NaPA-Loaded Sap Dispersion}

130 Sapx (2.47 g) was added into $80 \mathrm{~mL}$ of deionized water, and the mixture was stirred to form a 131 suspension ( $3 \mathrm{wt} \%$ Sap). A total of $30 \mathrm{~mL}$ of suspension was then transferred to a tube, and the remaining $50 \mathrm{~mL}$ of suspension was transferred and divided into five tubes with an equal volume of $10 \mathrm{~mL}$. After standing for $7 \mathrm{~d}$ at room temperature, Sap hydrogels were obtained. For the preparation of NaPA-loaded Sap dispersion, $0.25,0.50,0.75,1.0$, and $1.25 \mathrm{~mL}$ NaPA solution (4 $\mathrm{g} / \mathrm{L}$ ) was added into the above five $10 \mathrm{~mL}$ tubes separately. The corresponding mixtures of different concentrations were denoted Sapx-NaPAy, where $x$ represents the Si/Al ratio of the dispersed Sap at 5, 10, 15, 20, or 25 and y is the concentration of added NaPA at 0.10, 0.19, 0.28, 0.36 , or $0.44 \mathrm{~g} / \mathrm{L}$ aqueous Sap dispersion. For example, Sap20-NaPA0.44 indicates that the mixture was made by Sap20 with a concentration of NaPA at $0.44 \mathrm{~g} / \mathrm{L}$. To study the structure of the Sap after dispersion in the presence of NaPA, Sapx-NaPA0.44 (the concentration of NaPA in Sapx dispersion is $0.44 \mathrm{~g} / \mathrm{L}$ ) was dried at $80{ }^{\circ} \mathrm{C}$ to a constant weight. For comparison, Sap dispersions without adding NaPA were dried under the same conditions and used as a control. Such a sample was denoted Sapxcontrol.

\subsection{Powder X-ray Diffraction (XRD) and X-ray Fluorescence (XRF)}


$40 \mathrm{~mA}$, and a scanning range of $2-80^{\circ}$ were used. Elemental analyses of the samples (pressed powders) were carried out using an ARL ADVANT'X intelliPowertTM 4200 sequential X-ray fluorescence (XRF) analyzer. The layer charge density calculation of the structural formula was based on well-known assumptions about the structure of Sap (2:1 layer structure, 22 oxygen equivalence, all $\mathrm{Mg}$ assigned to an octahedral sheet, etc.).30

\subsection{Fourier infrared spectroscopy (FTIR)}

Fourier transform infrared spectra (FTIR) were recorded in transmission mode with a Nicolet 6700 FTIR spectrometer (Thermoelectric Nicolet, United States). Pressed disk samples were prepared by mixing the powdered solids with $\mathrm{KBr}$ in a pelleting device. All samples were measured at a wavenumber range of $400-4000 \mathrm{~cm}-1$ with 32 scans. The wavenumber accuracy was better than $0.01 \mathrm{~cm}^{-1}$, and the resolution was better than $0.09 \mathrm{~cm}-1$.

\subsection{Pore Structure Characterization}

The pore size distribution of Sap was detected on a Micromeritics ASAP2020 analyzer. Before the measurements, the Sap samples were degassed at $473 \mathrm{~K}$ for $10 \mathrm{~h}$ under a N2 flow.

\subsection{Scanning Electron Microscopy (SEM)}

For SEM characterization, the powder sample was mounted onto a conductive adhesive, coated in gold, and then analyzed on a Hitachi S-4700(II) scanning electron microscope.

\subsection{Rheological measurement}

The rheological properties of the Sap hydrogels were measured using a Malvern Kinexus Rheometer (Malvern Kinexus Lab+ Rheometer). The flow measurements were carried out at $25 \pm$ $0.1{ }^{\circ} \mathrm{C}$ using a rotational rheometer with a CP4/ 40 SR71SS cone-plate sensor; oscillatory measurements were carried out over a frequency range of $0.1-10 \mathrm{~Hz}$ at $25 \pm 0.1{ }^{\circ} \mathrm{C}$ using a stress control rheometer equipped with a CP4/40 SR71SS cone-plate sensor system. The data was analyzed using the rSpace software for the Kinexus rheometer.

\subsection{Zeta potential and dynamic light scattering (DLS) measurement}

. A fresh Sap dispersion was prepared by adding $1.22 \mathrm{~g}$ of Sap into $80 \mathrm{~mL}$ of deionized water. The zeta potential and particle size distribution of the synthetic saponite dispersion were performed with a Malvern Nano ZS90 instrument. 
178

179

180

181

182

183

184

185

186

187

188

189

190

191

192

193

194

195

196

197

198

199

200

201

202

203

204

205

206

207

208

209

210

211

212

213

\subsection{Mineralogy of Sap}

All synthetic samples (Figure 1c) exhibited reflections at $2 \theta 6.03,19.52,29.04,34.41$, and $60.37^{\circ}$, corresponding to the (001), (0211), (004), (1320), and (060) reflections of saponite, respectively.4 In particular, the position of the (060) reflection (d060 value) differentiates the structure of Al-enriched dioctahedral and Mg-enriched trioctahedral smectite.31 The d060 value of the series of synthetic samples was $0.153 \mathrm{~nm}$, indicating that the synthesized smectites have a trioctahedral structure (Figure 1a,b). This is in good agreement with the data reported in the literature that the d060 of the trioctahedral structure is higher than $0.152 \mathrm{~nm} .32,33$ As such, in this work, Sap with $\mathrm{Si} / \mathrm{Al}$ molar ratios of 5, 10, 15, 20, and 25 was successfully created with the hydrothermal process. The (001) reflections of the samples Sap5, Sap10, Sap15, Sap20, and Sap25 are 6.68, 6.13, 6.03, 5.88 , and $5.78^{\circ}$, corresponding to basal spacings of $1.33,1.44,1.46,1.50$, and $1.53 \mathrm{~nm}$, respectively. As the $\mathrm{Si} / \mathrm{Al}$ molar ratio increases from 5 to 25 , theoretically, the layer charge decreases from 1.33 to $0.35 \mathrm{e} / \mathrm{pfu}$ (Table 1 ). Thus, the layer charge density decreases. Usually, the basal spacing of smectite is controlled by the attractive and repulsive forces between two adjacent layers.34 As the layer charge increases, the electrostatic attraction increases more than the repulsive force. 8 Hence, the basal spacing followed the order Sap5 < Sap10 < Sap15 < Sap20 < Sap25. As the Si/Al molar ratio increased from 5 to 25 , the intensity of the (001) and (004) reflections decreased, whereas their full widths at half-maximum (FWHM) significantly decreased (Figure 1c). A similar trend was also observed for the (060) and (100) reflections. These observations indicated that the synthetic saponites with a lower $\mathrm{Si} / \mathrm{Al}$ ratio had superior crystallinity than those with a higher $\mathrm{Si} / \mathrm{Al}$ ratio. Thus, a $\mathrm{Si} / \mathrm{Al}$ molar ratio in the hydrothermal synthesis feedstock has a strong influence on the crystallinity of the resultant Sap. Decreasing the molar ratio of Si/Al favored Sap with larger crystal size and superior stacking order. As the Si/Al molar ratio inherently contributes to isomorphous substitution in the tetrahedral sheet of the saponite layer, greater content of $\mathrm{Al}$ in the tetrahedral sheet leads to superior crystallinity of the synthetic saponite.35 The successful formation of Sap was also confirmed by FTIR spectroscopy (Figure 1d). The characteristic absorption bands36 of Sap were observed at 3685, 1004, 800, 665, and $460 \mathrm{~cm}-1$. The absorption band at $3685 \mathrm{~cm}^{-1}$, which arose from the stretching vibrational modes of $\mathrm{Mg}-\mathrm{OH}$, is a typical characteristic of trioctahedral clay minerals. 37 The broad band centered at $3440 \mathrm{~cm}^{-1}$ and the band at $1645 \mathrm{~cm}^{-1}$ were both due to adsorbed water molecules. The decrease of the band at $800 \mathrm{~cm}-1$, due to tetrahedral $\mathrm{Al}-\mathrm{O}$ vibrations from Sap5 to Sap25, indicated a decrease of the tetrahedral $\mathrm{Al}$ content according to the chemical composition of the synthetic saponites (Table 1). The band at $1058 \mathrm{~cm}-1$ reflects the stretching vibration of the $\mathrm{Si}-\mathrm{O}-\mathrm{Si}$. The slight shift of this band from Sap5 to Sap25 also indicated a decrease of tetrahedral substitutions.38 
When a Sap is dispersed in water, it forms a colloid. In particular, the colloids of Sap10, Sap15, Sap20, and Sap25 appeared to be strongly optically transparent. After standing for $7 \mathrm{~d}$, samples Sap10-Sap25 formed hydrogels (Figure S1aI). When the tubes were put upside down, the gels remained in place unless vibration (shear force) was applied. In contrast, Sap5 failed to form a hydrogel. This can be ascribed to the better crystallinity and higher layer charge of Sap5. In addition, the average particle size of the Sap5 is 2-3 times larger than that of the other Sap (Table 1). Such Sap easily sedimented in suspension. The better crystallinity and layer charge make it difficult to delaminate; thus, it failed to form stable dispersions. Due to Tyndall scattering, a bright path in the hydrogels (Figure 2cI) of Sap10, Sap15, Sap20, and Sap25 can be observed. This suggests that the Sap had delaminated in the aqueous dispersion because of the electrostatic repulsion of Sap particles and thus existed as nanoparticles. Only colloids of Sap5 kept the form of a sol and did not form a gel. Thus, the rheological properties of Sap5 were not measured in the following experiments. Under a nonsteady state, the viscosity of the Sap hydrogel (3 wt \%) as a function of shear rate (Figure 2a) suggested that the hydrogels showed distinct shear-thinning behaviors. At the lowest shear rate of $0.1 \mathrm{~s}-1$, the viscosities of the Sap hydrogels of Sap10, Sap15, Sap20, and Sap25 were 132.3, 149.6, 241.8, and $306.2 \mathrm{~Pa} \cdot \mathrm{s}$, respectively. As the shear rate increased to $100 \mathrm{~s}-1$, the viscosity decreased. At a fast decrease from 0.1 to $2.512 \mathrm{~s}-1$, the viscosity decreased rapidly, and finally, the viscosity reached a minimum and tended to be equal for all four samples. A possible reason for the observed decrease of viscosity with increasing shear rate was that the house-of-card structure, with edge-to-face interactions between Sap nanolayers, was destroyed by shear force,39 causing the direction of the delaminated layer of Sap in the hydrogel to gradually change to the direction of flow under shear force, resulting in the decreasing viscosity. At a shear rate of $100 \mathrm{~s}-1$, the viscosity of the aqueous Sap dispersions approached zero, revealing a typical shear-thinning process. The solidlike gel thus transformed to liquidlike sol at the highest shear rates. At a given shear rate, Sap samples with a higher layer charge density had lower-viscosity hydrogels. Sap20 and Sap25 resulted in hydrogels with greater swelling. A similar conclusion that greater charge density led to stronger cohesive strength between the layers, thus decreasing swelling, was also drawn in the literature. 40 Thus, that the layer charges of $0.53 \mathrm{e} / \mathrm{pfu}$ (Sap15) to $0.35 \mathrm{e} / \mathrm{pfu}$ (Sap25) resulted in greater swelling is a well-accepted deduction. Generally, because the Sap particles delaminate to isolated mono, or at least partially, delaminated multilayers, the increase in layer charge resulted in less delamination of Sap particles.41 246 Experimental results of shear rate versus viscosity can be fitted to the Sisko42 model (Figure S1a). $247 \eta=\eta \infty+\mathrm{k} \gamma \mathrm{n}-1$, where $\eta \infty$ denotes the infinite-rate viscosity in $\mathrm{Pa} \cdot \mathrm{s}, \mathrm{k}$ is a constant, $\mathrm{n}$ is a rate index, and $\gamma$ represents shear rate. At a low shear rate, the house-of-card structure of Sap in a hydrogel strongly hinders rotation, thus requiring appreciable torque to initiate flow with the 
rate increased. According to the Sisko model, at a shear rate of $100 \mathrm{~s}-1$, the Sap hydrogel approached infinite viscosity $(\eta \infty)$.

Shear stress, as a function of the shear rate (Figure 2b) of Sap (Sap10, Sap15, Sap20, and Sap25) hydrogels ( $3 \mathrm{wt} \%$ ), showed similar behavior to non-Newtonian fluids.43 At a shear rate of 0.1 $\mathrm{s}^{-1}$, the shear stresses of the hydrogels of Sap10 and Sap15 were 13.24 and 14.96 Pa, whereas the shear stresses of Sap20 and Sap25 were 24.18 and $32.94 \mathrm{~Pa}$, respectively. The data indicated that shear stress is closely related to the layer charge density of Sap. The shear stress increased with the decrease of layer charge density from Sap10 to Sap25. Inherently, higher shear stress means that the particle-particle associations require higher energy to break and/or a faster rate of bond formation over shear-initiated breakage. These interactions are decided by the layer charge density and particle size of Sap. In this context, according to $\sigma=\mathrm{EK}(\mathrm{N} 2 / 2)$ (where $\sigma$ is shear stress, E is the energy of the bond, $\mathrm{K}$ is a rate constant for bond formation and breakage, and $\mathrm{N}$ is the number of particles per $\mathrm{cm} 3$ that are constantly forming and breaking bonds during the shear/flow process), 44 and provided that the bond energy between Sap particles and the rates at which bonds form and break are almost constant in the hydrogel of the Sap20 and the Sap25, the number of bonds forming and breaking will play a larger role in shear stress than that in the Sap10 and the Sap15. Since all dispersions were completed at the same solid concentration, any changes in the number of bonds forming or breaking can be attributed to differences in particle size (number of layers associated with each quasicrystal). The number of layers associated with each quasicrystal can be then related to layer charge as discussed above. Furthermore, as (plastic) viscosity is represented by the slope of the shear stress curve, $\sigma=\sigma \mathrm{e}+\eta \Omega$ (where $\sigma \mathrm{e}$ is the extrapolated shear stress, $\eta$ is viscosity, and $\Omega$ is the shear rate), 45 viscosity is also influenced strongly by $N$. It worth noting that at a shear rate of $1.45 \mathrm{~s}-1$, Sap20 and Sap25 followed a typical plastic flow, whereas dilatant flow behavior was observed for Sap10 and Sap15. The phenomena implied that, given the higher layer charges for Sap10 and Sap15 resulting in larger particles, above a threshold shear force, delamination of Sap particles occurred and thus increased swelling resulted in increased dispersion viscosity. Experimental results of shear rate versus shear stress can be fitted to the Herschel-Bulkley model.46 $\tau=\tau 0+\mathrm{k} \gamma \mathrm{n}$, where $\tau 0, \mathrm{k}$, and $\mathrm{n}$ are the Herschel-Bulkley yield stress, the consistency index, and the flow index parameters, respectively. The model also indicates that, under a certain shear force, delamination of Sap10 and Sap15 layers occurred and thus led to increased swelling when dispersed. The dispersion of Sap10 and Sap15 flowed because of their higher layer charge and larger particles. Regarding Sap20 and Sap25, both exhibited plastic or Bingham flowing behavior. A linear response above the critical shear rate means that the rate of energy dissipation per unit volume is at equilibrium with the rate of shear. By contrast, for Sap10 and Sap15 dispersions, only the rate of energy dissipation per unit volume is at equilibrium with a shear rate of $1.45 \mathrm{~s}-1$. Under a nonsteady state, the Sap hydrogels displayed thixotropy (Figure 2c), as the plots of shear stress versus shear rate exhibited characteristic hysteresis 47 and revealed that all Sap hydrogels are non-Newtonian fluids. Thixotropy is defined as the area within 
the flow curve loop, increasing and then decreasing with the applied shear rate. Thixotropy values for Sap10 and Sap15 hydrogels were 4830 and $4643 \mathrm{~Pa} \cdot \mathrm{s}-1$, whereas for Sap20 and Sap25 hydrogels were 10573 and $7706 \mathrm{~Pa} \cdot \mathrm{s}-1$, respectively, in the shear rate range of $1.45-1000 \mathrm{~s}-1$. Sap20 had the largest thixotropic loop area and also displayed the highest shear stress. The larger area of the thixotropic loop for Sap20 and Sap25 hydrogels revealed that they exhibited a stronger thixotropy than Sap10 and Sap15 hydrogels. Such differences in thixotropy might be caused by the distinct particle associations in sample Sap20 as observed by SEM (Figure 7g). Theoretically, in the Sap gel, equilibrium is never achieved between the bond formation and bond breakage, as the Sap system undergoes shear. In regard to Sap10 and Sap15 hydrogels, the lack of oscillations indicates that equilibrium conditions are essentially met. Some further evidence of thixotropic behavior being affected by layer charge density and particle size (inherently particle associations and bonding) can be seen as oscillations in the shear responses within the hysteresis loops (Figure $2 \mathrm{~d})$. The storage modulus $\left(\mathrm{G}^{\prime}\right)$ reflects the energy storage and elastic properties of the material after perturbation.48 The loss modulus $\left(\mathrm{G}^{\prime \prime}\right)$ reflects the energy loss and viscous properties of the material through the relaxation or dissipation of energy (usually as heat).49 For the four samples, the $\mathrm{G}^{\prime}$ exceeded the $\mathrm{G}^{\prime \prime}$ at a frequency ranging from 1 to $10 \mathrm{~Hz}$ at $25 \pm 0.1{ }^{\circ} \mathrm{C}$ and indicated that the Sap dispersions behave as hydrogels.50 In other words, they tended to form bonds and decrease $\mathrm{N}$ over time. The hydrogel formed by the Sap20 possessed the highest $\mathrm{G}^{\prime}$ and $\mathrm{G}^{\prime \prime}$.

\subsection{Crystallinity and morphology of Sap}

All of the Sap samples exhibited a plated morphological structure as observed in SEM images (Figure 7). For the SEM images of Sap5 (Figure S7), slices of curved plates with well-defined edges can be clearly observed, indicating that well-crystallized layered saponite was achieved.34 Compared to Sap5, the Sap10 samples consist of smaller secondary and primary Sap particles (Figure 7a). Thus, incorporation of less Al into the Sap framework hampered the formation of large plates. This trend was more obvious for the Sap15 (Figure 7b). In particular, Sap20 (Figure 7c) has a larger size than the other Sap, except for Sap5, possibly a result of distinct aggregation. This distinction has been found in the measurement of the thixotropic behavior of the gel from aqueous Sap20 dispersion (Figure 5). The SEM image of the Sap25 (Figure 7d) also showed a platy morphology. The results (Table 1) obtained from dynamic light scattering (DLS) also revealed that Sap20 behaved differently when compared with the others. The average particle sizes of Sap5, Sap10, Sap15, Sap20, and Sap25, as measured by DLS, were 502, 171, 148, 245 , and $144 \mathrm{~nm}$, respectively. Particle size decreased gradually with an increasing Si/Al molar ratio from 5 to 15 but increased by ca. $100 \mathrm{~nm}$ for Sap20. These results correlate well with SEM observations and rheology results. Moreover, the pore structure of Sap20 appeared different. The average pore diameters of Sap5, Sap10, Sap15, Sap20, and Sap25 were 3.61, 3.68, 3.34, 3.08, and $3.16 \mathrm{~nm}$, respectively (Figure S8). The Barrett-Joyner-Halenda desorption cumulative pore volumes of Sap5, Sap10, Sap15, Sap20, and Sap25 between 2.05 and $3.10 \mathrm{~nm}$ were 0.0122 , $0.0118,0.0416,0.0624$, and $0.0490 \mathrm{~cm} 3 / \mathrm{g}$, respectively. The differences in particle size and pore 
structure are related to the formed hydrogel. The hydrogel strength (selling pressure) is much stronger in Sap20 than the others. In Sap-water systems, an electronic double layer was made up of the negative surface charge and the balancing cation charge. As discussed above, for all Sap samples, the negative charge of the Sap layer is a consequence of isomorphous substitutions within the saponite crystal lattice. The counterions were electrostatically attracted by the oppositely charged surface (Figure 2e) but had a tendency to diffuse away from the surface to the bulk solution where its concentration is lower. The concentration of the counterions near the Sap particle surface was high, and it decreased with increasing distance away from the surface of the Sap particle. The diffuse layer did not only consist of an excess of opposite ions but also a deficiency of anions near the surface, as the ions with the same charge were electrostatically repelled by the surface of the Sap particle. Here, in the sap-water suspension system, the cations were adsorbed onto the surface of Sap particles and, together with the counterions, formed a diffuse double layer (Figure 2e). The higher charge potential at the Sap surface overrode the tendency for the cations to hydrate with water, so the charge was more effectively neutralized and the diffuse double layer contracted. As such, the (absolute value of) $\zeta$-potential of Sap dispersion also appeared to be higher for the Sap carrying a higher layer charge density (Figure 5a). The gel-forming ability of the dispersion of Sap in water was affected by both the layer charge density of Sap and the relevant associations and connections of Sap particles. For the lowest layer charge density, Sap can be more easily dispersed and delaminated in water to form a house-of-card structure. Such gels displayed higher viscosity and thixotropy, explaining why the Sap20 hydrogel exhibited the largest area of a thixotropic loop (Figure 2c) and the Sap25 hydrogel exhibited the highest viscosity. This implies that the thixotropic rheological properties of the Sap gel were closely related to the chemical composition of Sap and association modes between the Sap particles into water.

\subsection{Rheological behavior affected by sodium polyacrylate}

For the purpose of tuning the shear thinning of Sap hydrogels and studying the influence of the NaPA on the different Sap hydrogels, NaPA with concentrations of 0.1, 0.19, 0.28, 0.36, and 0.44 $\mathrm{g} / \mathrm{L}$ was loaded into the Sap hydrogels. The infinite viscosity of the Sap-NaPA dispersions tends to zero. This phenomenon indicated that the addition of NaPA induced shear thinning (Figure 3a-d). In regard to Sap-NaPA0.1 dispersions made from Sap10, Sap15, Sap20, and Sap25 hydrogels with added $\mathrm{NaPA}$ at a concentration of $0.1 \mathrm{~g} / \mathrm{L}$, the viscosity decreased rapidly as the shear rate increased from 0 to $2.5 \mathrm{~s}-1$. Comparing the Sap10-NaPA0.1 dispersion to dispersions of Sap15-NaPA0.1, Sap20-NaPA0.1, and Sap25-NaPA0.1, the decline in viscosity was much slower and may be due to the higher layer charge density of Sap10 (0.74 e/pfu). For all SapNaPA dispersions, as the shear rate increased from 2.5 to $10 \mathrm{~s}-1$, the viscosity declined slowly. When the shear rate increased to more than $10 \mathrm{~s}-1$, all Sap-NaPA dispersions were similar to liquids with very low viscosity, especially at the equilibrium viscosity. The result suggested that the effect of NaPA on Sap hydrogels was less significant at very high mechanical forces and the addition of 
NaPA weakened the particle-to-particle connections between Sap particles in hydrogels. Furthermore, the Sap dispersions in the presence of NaPA are well fitted with the Sisko model (Figure S2a-d). The infinite viscosity of the Sap-NaPA dispersions tends to zero, indicating that the addition of NaPA induced shear thinning. Shear stress as a function of shear rate for different SapNaPA dispersions is shown in Figure 4. The results of shear stress versus shear rate showed that the Sap-NaPA dispersion followed a plastic flow and fit the Herschel-Bulkley $\tau=\tau 0+\mathrm{k} \gamma \mathrm{n}$ model46 (Figure S3a-d). The shear stress of all Sap-NaPA dispersions decreased with the increase of the concentration of the NaPA (Figure $4 a-d$ ). In addition, it was noted that the shear stress increased with increasing shear rate, except for Sap10-NaPA0.1, in which the shear rate had an indistinctive influence on shear stress (Figure S3a). The reason is that the layer charge density of Sap10 $(0.74 \mathrm{e} / \mathrm{pfu})$ is higher than the others. The low concentration $(0.1 \mathrm{~g} / \mathrm{L})$ of NaPA had an insignificant influence on the hydrogel formation for Sap10.

Without adding NaPA in Sap hydrogels, the yield stresses ( $\tau 0)$ of Sap10 and Sap15 were 13.35 and 14.93 Pa, respectively, whereas they were 29.33 and 66.17 Pa for Sap20 and Sap25, respectively. When the concentration of added NaPA was $0.1 \mathrm{~g} / \mathrm{L}$, the yield stresses $(\tau 0)$ of Sap10-NaPA0.1 and Sap15-NaPA0.1 were 7.09 and 7.38 Pa, respectively, whereas they were 13.32 and 25.65 Pa for Sap20-NaPA0.1 and Sap25-NaPA0.1, respectively. With an increased NaPA concentration, the yield stress $\tau 0$ decreased gradually and tended toward zero, indicating that the Sap hydrogel tended to be sol when NaPA was added. The Sap20 and Sap25, with a lower layer charge density than Sap10 and Sap15, were more difficult to flow for their hydrogels and dispersions with addition of NaPA. The thixotropic behavior of Sap dispersions was also affected by NaPA. For all Sap-NaPA dispersions, the dispersions are still thixotropic (Figure S4a-d). NaPA concentration had no observable effect on the area of the thixotropic loop for Sap20- NaPa, but the areas of the Sap20-NaPA complexes were reduced significantly compared to that of the Sap20 hydrogel. The same phenomenon was observed for Sap25-NaPA dispersion. Such results in thixotropy suggested that the concentrations of NaPA had an indistinctive influence on thixotropy for Sap20 and Sap25 hydrogels. The shear thinning and thixotropy of Sap dispersions derived from the characteristics of the network formed by Sap particles; the network was destroyed as the shear rate increased. In contrast, when the shear rate decreased, the aggregation of Sap layers could be rebuilt to be a whole network. The frequency response of the $\mathrm{G}^{\prime}$ and the $\mathrm{G}^{\prime \prime}$ of the Sap dispersions in the presence of NaPA is shown in Figure S5a-d.

For all Sap-NaPA dispersions, as the frequency increased, $\mathrm{G}^{\prime}$ was first lower than $\mathrm{G}^{\prime \prime}$ and then $\mathrm{G}^{\prime}$ became higher than $\mathrm{G}^{\prime \prime}$. Compared to Sap dispersions without the addition of NaPA, the $\mathrm{G}^{\prime}$ at the analyzed frequencies decreased by several orders of magnitude and the $\mathrm{G}^{\prime \prime}$ was higher than the $\mathrm{G}^{\prime}$ at lower frequencies. In other words, adding NaPA in the Sap dispersion led to a viscoelastic liquidlike sol.51 This sol was not a pure viscous fluid at the analyzed frequencies. The elastic component of the viscoelastic sol indicated a tendency to gel.52 Based on the discussion of the above results, it can be concluded that the addition of NaPA induced changes in the rheological 
properties of Sap hydrogels. After adding NaPA into the Sap hydrogel system, the Sap hydrogels transformed to sols by weakening the connections between Sap particles, resulting in a decrease in the viscosity and thixotropy of Sap dispersions.

\subsection{Interaction between the anionic polyelectrolyte and Sap}

The $\zeta$-potential of $1.5 \mathrm{wt} \%$ Sap dispersions was plotted as a function of NaPA concentration (Figure 5a). The $\zeta$ potential of all Sap samples is less than $-38 \mathrm{mV}$. Sap with a higher layer charge displayed a higher $\zeta$-potential. At a given NaPA concentration, the $\zeta$-potential of Sap10 (0.74 e/pfu)

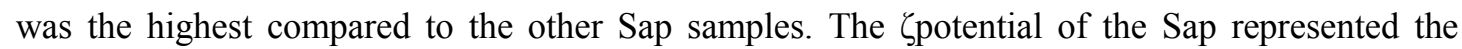
change in the layer charge of the particles as a function of their composition. Over the entire range of NaPA concentrations, the $\zeta$-potential values indicated a strong negative charge on the surface of Sap particles. The $\zeta$-potential of negative charge increased significantly as the NaPA gradually covered the surface of the particles. Thus, NaPA increased electrostatic repulsion between Sap particles and promoted the stabilization of Sap dispersion.53 The rheological properties of Sap with addition of NaPA changed, which can be described as the Hofmeister effect.54 The FTIR spectra of the dried samples, which were made from the Sap dispersions with an added $0.44 \mathrm{~g} / \mathrm{L}$ NaPA, are similar to those of the samples without added NaPA (Figure S6), except that the presence of NaPA could be observed in the Sap25-NaPA0.44 sample (Figure S6d). The bonds at 1559 and $1325 \mathrm{~cm}-1$ are ascribed to the symmetrical stretching vibrations of $\mathrm{COO}-$. The bond at $1407 \mathrm{~cm}-1$ is due to the $\mathrm{C} \square \mathrm{O}$ bending in carboxylate groups. Those bonds were also detected in Sap25-NaPA0.44. Notably, no change in the vibration bands could be observed, revealing that the addition of NaPA did not generate new chemical bonds. The presence of NaPA in the Sap25-NaPA0.44 is probably the adsorption of NaPA on the surfaces of Sap25 by electrostatic attraction and hydrogen bonding. To better illustrate the interaction between NaPA and Sap, a possible schematic illustration is proposed (Figure 5). NaPA has a carboxylate functional group, which ionizes in water (Figure 5bI); thus, it can be dissociated to form PA-. Due to the surface charge in the vicinity of the Sap particle, an electric field strength formed.55 Under such an electric field, the negatively charged PA- underwent an instantaneous polarization, 56 which can enter into the Sap hydration sphere faster than the original hydrated ions. PA- would electrostatically interact with the exchange cations as PA- and can approach closer to the cations than the cations to the surface of the clay (due to water). PA- displaced water and formed a strong bond because of the stronger electrostatic attraction. At these very low NaPA concentrations, the PA- interacts with the exterior surfaces of the Sap quasicrystals but eventually by mass action enables delamination. Consequently, after adding NaPA into the Sap hydrogel, the Sap hydrogel transformed into a Sap dispersion resulting from the destruction of the original network structure (Figure 5bII). The destruction of the network structure can be ascribed to the electrostatic attraction between polarized PA- and negatively charged Sap particles and possible hydrogen 
bonding between broken bonds, $\mathrm{Mg}-\mathrm{O}$ and $\mathrm{Si}-\mathrm{O}$, at the edges of tetrahedral/octahedral sheets of Sap and hydrogen atoms on PA-. Another possible reason is when NaPA was introduced into the Sap hydrogel system, the width of the diffuse layer increased because PA- has a larger molecular size than original hydrate ions. Additionally, to further investigate the interaction between Sap and NaPA, powder XRD and SEM were carried out for Sap-control (dried from the Sap hydrogel) and Sap-NaPA (dried from the Sap hydrogel after adding NaPA). Comparing XRD pattern of Sap10-NaPA0.44 (dried from Sap10 dispersions, after adding NaPA at the concentration of 0.44 $\mathrm{g} / \mathrm{L}$ ) with that of the Sap10-control, the intensity of the (001) reflection increased and the full widths at half-maximum (FWHM) significantly decreased for Sap10-NaPA0.44 samples (Figure 6a). Such results can indicate that the addition of NaPA induced a better coherency in the $\mathrm{c}$ dimension for Sap10 layers, i.e., a higher number of Sap layers stacked. Regarding the other SapNaPA0.44 (dried from Sapx dispersions, where $\mathrm{x}$ is 15, 20, or 25 mole\% Al in Sap, after adding NaPA at the concentration of $0.44 \mathrm{~g} / \mathrm{L}$ ), the intensity of the (001) reflection increased but the FWHM significantly increased when compared with their corresponding Sap-control (Figure $6 \mathrm{~b}-\mathrm{d})$. The results indicate that PA- was able to penetrate the interlayer, resulting in delamination. The SEM observations of Sap-NaPA0.44 revealed that these Sap samples have a more compact and ordered layer structure than the raw Sap (Figure 7). Sap in the water system dispersed and formed hydrogels after standing for $7 \mathrm{~d}$ and dried from dispersions reassembled in the first instance (Figure 7e-h). A schematic illustration of Sap dispersion with/without added NaPA and reaggregation after drying is presented in Figure $5 \mathrm{c}$ to clarify the interaction process between Sap, water, and NaPA. After adding NaPA into the Sap hydrogel, the house-ofcard structure was destroyed and the Sap hydrogel became more dispersed (Figure 5cVI). When the Sap-NaPA0.44 dispersion was dried, the dispersed Sap particles reassembled in a more ordered, regular, and compact structure (Figure 5cVII). Interestingly, as seen in Figure 7g, Sap20-NaPA0.44 exhibited the best compact structure among the Sap-NaPA0.44 samples, suggesting that the reassembly/reaggregation of negatively charged Sap layers reacted with polarized PA-, which may be caused by the strength of the Sap layer charge density. The Sap20 with the layer charge density of $0.42 \mathrm{e} / \mathrm{pfu}$ delaminated best in a water/NaPA system and reassembled/ reaggregated better than the other Sap with unmatched layer charge density. Such results further confirmed that the NaPA not only affected the rheological properties of Sap dispersion but also promoted the reassembled Sap to form a superior crystal structure by interacting with the Sap hydration sphere in Sap dispersion.

\section{Conclusion} simple hydrothermal process. The $\mathrm{Si} / \mathrm{Al}$ molar ratio had a remarkable influence on the crystallinity, 
morphology, and particle size of the synthetic Sap. The lowest Si/Al molar ratio (5) led to improved Sap crystallinity. However, for this lowest ratio, the synthetic Sap did not delaminate easily, probably due to a high layer charge, and was unable to form gel in aqueous dispersion. On the other hand, the aqueous dispersions ( 3 wt \%) of synthetic Sap, with a Si/Al molar ratio ranging from 10 to 25, formed gel spontaneously. The Sap hydrogel had remarkable rheological properties that were related to the chemical composition and inherently to its crystallinity, layer charge, and particle size. The hydrogel from the Sap with a Si/Al molar ratio of 25 exhibited the highest viscosity, which was ascribed to better delamination and the formation of an open house-of-card structure with stronger connections of delaminated Sap particles compared to the other synthetic Sap. The addition of the anionic polyelectrolyte NaPA decreased the viscosity and reduced the thixotropic properties of the Sap hydrogel. Moreover, the addition of NaPA caused the hydrogel to become sol. The aqueous dispersion of the Sap with NaPA formed a stable sol, compared to the Sap sol or Sap hydrogel. The colloidal stabilization of Sap by NaPA is considered to be due to the Hofmeister effect. In the hydrogel, electrostatic interactions between synthetic Sap particles and NaPA occurred. The anionic NaPA could be instantaneously polarized under the electric field of Sap particles and, as a result, quickly entered the hydration layer of Sap particles to disrupt the structure of Sap gel, thereby changing the Sap dispersion in water. Such effects of sodium polyacrylate can be further investigated to finely tune the rheological behaviors of synthetic saponite hydrogels and can be used to exfoliate swelling clay minerals into 2D nanosheets.

The authors wish to acknowledge the financial support from the National Natural Scientific Foundation of China (41672033; 21373185), the financial support by the open fund from Key Laboratory of High Efficient Processing of Bamboo of Zhejiang Province, China National Bamboo Research Center,,Key Laboratory of Clay Minerals of Ministry of Land and Resources of the People's Republic of China, Engineering Research Center of Non-metallic Minerals of Zhejiang Province, Zhejiang Institute of Geology and Mineral Resource, China (ZD2018K05), and the State Key Laboratory Breeding Base of Green Chemistry-Preparation Technology, Zhejiang University of Technology (GCTKF2014006). 
(1) Newman, A.C.D.; Brown, G. The Chemical Composition of Clays. In Chemistry of Clays and Clay Minerals; Newman, A.C.D., Ed.; The Mineralogical Society: London, 1987; Chapter 1, Vol. p1-128, pp 480.

(2) Bergaya, F.; Lagaly, G. Chapter 1 - General Introduction: Clays, Clay Minerals, and Clay Science. In Developments in Clay Science, Second Edition. Handbook of Clay Science; Bergaya, F.; Bergaya, F.; Lagaly, G., Eds.; Elsevier, 2013; Vol. 1, pp 1-19.

(3) Tao, Q.; Fang, Y.; Li, T.; Zhang, D.; Chen, M.; Ji, S.; He, H.; Komarneni, S.; Zhang, H.; Dong, Y.; Noh, Y. D. Silylation of saponite with 3-aminopropyltriethoxysilane. Appl. Clay Sci. 2016, 132-133, 133-139.

(4) Takagi, S.; Shimada, T.; Ishida, Y.; Fujimura, T.; Masui, D.; Tachibana, H.; Eguchi, M.; Inoue, H. Size-Matching Effect on Inorganic Nanosheets: Control of Distance, Alignment, and

Orientation of Molecular Adsorption as a Bottom-Up Methodology for Nanomaterials. Langmuir 2013, 29, 2108-2119.

(5) Huang, J.; Wang, L.; Li, T.; Shao, J. Rheological studies of mineral clay and its application in reactive dye printing of cotton. Text. Res. J. 2017, 88, 614-620.

(6) Zhen, W.; Lu, C.; Li, C.; Liang, M. Structure and properties of thermoplastic saponite/poly(vinyl alcohol) nanocomposites. Appl.Clay Sci. 2012, 57, 64-70.

(7) Bernardini, F.; Sibilia, E.; Kasztovszky, Z.; Boscutti, F.; De Min, A.; Lenaz, D.; Turco, G.; Micheli, R.; Tuniz, C.; Montagnari Kokelj, M. Evidence of open-air late prehistoric occupation in the Trieste area (north-eastern Italy): dating, 3D clay plaster characterization and obsidian provenancing. Archaeol. Anthropol. Sci. 2018, 10, 1933-1943.

(8) Dazas, B.; Lanson, B.; Delville, A.; Robert, J.-L.; Komarneni, S.; Michot, L. J.; Ferrage, E. Influence of tetrahedral layer charge on the organization of interlayer water and ions in synthetic Na-saturated smectites. J. Phys. Chem. C 2015, 119, 4158-4172.

(9) Bergaya, F.; Lagaly, G. Chapter 7.1 - Purification of Natural Clays. In Developments in Clay Science Edition. 2nd Edition Handbook of Clay Science; Bergaya, F.; Lagaly, G., Eds.; Elsevier: Amsterdam, 2013; Vol. 5, pp 213-221.

(10) Gebretsadik, F. B.; Mance, D.; Baldus, M.; Salagre, P.; Cesteros, Y. Microwave synthesis of delaminated acid saponites using quaternary ammonium salt or polymer as template. Study of pH influence. Appl. Clay Sci. 2015, 114, 20-30.

(11) Garciano, L. O.; Tran, N. H.; Kannangara, G. S. K.; Milev, A. S.; Wilson, M. A.; Volk, H. Developing saponite supported cobalt- molybdenum catalysts for upgrading squalene, a hydrocarbon from the microalgae Botryococcus braunii. Chem. Eng. Sci. 2014, 107, 302-310.

(12) Vogels, R. J. M. J.; Kloprogge, J. T.; Geus, J. W. Synthesis and characterization of saponite clays. Am. Mineral. 2005, 90, 931-944.

(13) Intachai, S.; Khaorapapong, N.; Ogawa, M. Hydrothermal synthesis of zinc selenide in smectites. Appl. Clay Sci. 2017, 135, 45- 51.

(14) Suquet, H.; Iiyama, J. T.; Kodama, H.; Pezerat, H. Synthesis and Swelling Properties of Saponites with Increasing Layer Charge. Clays Clay Miner. 1977, 25, 231-242.

(15) Gebretsadik, F. B.; Salagre, P.; Cesteros, Y. Use of polymer as template in microwave synthesis of saponite. Study of several factors of influence. Appl. Clay Sci. 2014, 87, 170-178. (16) Bergada, O.; Vicente, I.; Salagre, P.; Cesteros, Y.; Medina, F.; Sueiras, J. E. Microwave effect during aging on the porosity and basic properties of hydrotalcites. Microporous Mesoporous Mater. 2007, 101, 363-373. 
(17) Vogels, R. J. M. J.; Kerkhoffs, M. J. H. V.; Geus, J. W. Nonhydrothermal Synthesis, Characterisation and Catalytic Properties of Saponite Clays. In Studies in Surface Science and Catalysis; Poncelet, G.; Martens, J.; Delmon, B.; Jacobs, P. A.; Grange, P., Eds.; Elsevier, 1995; Vol. 91, pp 1153-1161.

(18) Zhou, C. H.; Zhou, Q.; Wu, Q. Q.; Petit, S.; Jiang, X. C.; Xia, S. T.; Li, C. S.; Yu, W. H. Modification, hybridization and applications of saponite: An overview. Appl. Clay Sci. 2019, 168, 136-154.

(19) Makarchuk, O. V.; Dontsova, T. A.; Astrelin, I. M. Magnetic nanocomposites as efficient sorption materials for removing dyes from aqueous solutions. Nanoscale Res. Lett. 2016, 11, No. 161.

(20) Chen, L.; Zhou, C. H.; Fiore, S.; Tong, D. S.; Zhang, H.; Li, C. S.; Ji, S. F.; Yu, W. H. Functional magnetic nanoparticle/clay mineral nanocomposites: preparation, magnetism and versatile applications. Appl. Clay Sci. 2016, 127-128, 143-163.

(21) Annan, E.; Kan-Dapaah, K.; Azeko Salifu, T.; Mustapha, K.; Asare, J.; Zebaze Kana, M. G.; Soboyejo, W. Clay mixtures and the mechanical properties of microporous and nanoporous ceramic water filters. J. Mater. Civ. Eng. 2016, 28, No. 04016105.

(22) Tao, Q.; Chen, M.; He, H.; Komarneni, S. Hydrothermal transformation of mixed metal oxides and silicate anions to phyllosilicate under highly alkaline conditions. Appl. Clay Sci. 2018, $156,224-230$.

(23) Tombacz, E.; Szekeres, M. Colloidal behavior of aqueous' montmorillonite suspensions: the specific role of $\mathrm{pH}$ in the presence of indifferent electrolytes. Appl. Clay Sci. 2004, 27, 75-94. (24) Grandjean, J.; Robert, J.-L. Multinuclear magnetic resonance studies on aqueous suspensions of synthetic saponites. J. Colloid Interface Sci. 1997, 187, 267-273.

(25) Gao, X.; Li, S.; Liu, X.; Hu, F.; Tian, R.; Li, H. The effects of NO3 - and Cl- on negatively charged clay aggregation. Soil Tillage Res. 2019, 186, 242-248.

(26) Güngör, N. Effect of the adsorption of surfactants on the rheology of Na-bentonite slurries. J. Appl. Polym. Sci. 2000, 75, 107- 110.

(27) Shaikh, S. M.; Nasser, M. S.; Hussein, I.; Benamor, A.; Onaizi, S. A.; Qiblawey, H. Influence of polyelectrolytes and other polymer complexes on the flocculation and rheological behaviors of clay minerals: A comprehensive review. Sep. Purif. Technol. 2017, 187, 137-161.

(28) Tong, K.; Song, X.; Sun, S.; Xu, Y.; Yu, J. The rheological behavior and stability of $\mathrm{Mg}(\mathrm{OH}) 2$ aqueous suspensions in the presence of sodium polyacrylate. Colloids Surf., A 2013, 436, 11111120 .

(29) Fu, L.-h.; Cao, T.-h.; Lei, Z.-w.; Chen, H.; Shi, Y.-g.; Xu, C. Superabsorbent nanocomposite based on methyl acrylic acid-modified bentonite and sodium polyacrylate: Fabrication, structure and water uptake. Mater. Des. 2016, 94, 322-329.

(30) Kaufhold, S.; Plötze, M.; Klinkenberg, M.; Dohrmann, R. Density and porosity of bentonites. J. Porous Mater. 2013, 20, 191- 208.

(31) Wang, W.; Zhen, W.; Bian, S.; Xi, X. Structure and properties of quaternary fulvic acid-intercalated saponite/poly(lactic acid) nanocomposites. Appl. Clay Sci. 2015, 109-110, 136-142.

(32) Chemtob, S. M.; Nickerson, R. D.; Morris, R. V.; Agresti, D. G.; Catalano, J. G. Synthesis and structural characterization of ferrous trioctahedral smectites: Implications for clay mineral genesis and detectability on Mars. J. Geophys. Res.: Planets 2015, 120, 1119-1140. 
(33) Brown, G.; Brindley, G. W. Chapter 5 - X-ray Diffraction Procedures for Clay Mineral Identification.In Mineralogical Society Monograph; Brindley, G.; Brown, G., Eds.; Mineralogical Society: London, 1980; Vol. 5, pp 305-359.

(34) Rajapakse, R.; Murakami, K.; Bandara, H.; Rajapakse, R.; Velauthamurti, K.; Wijeratne, S. Preparation and characterization of electronically conducting polypyrrole-montmorillonite nanocomposite and its potential application as a cathode material for oxygen reduction. Electrochim. Acta 2010, 55, 2490-2497.

(35) He, H.; Li, T.; Tao, Q.; Chen, T.; Zhang, D.; Zhu, J.; Yuan, P.; Zhu, R. Aluminum ion occupancy in the structure of synthetic saponites: Effect on crystallinity. Am. Mineral. 2014, 99, 109-116.

(36) Madejova, J.; Gates, W. P.; Petit, S. Chapter 5 - IR Spectra of Clay Minerals Developments in Clay Science, Infrared and Raman Spectroscopies of Clay Minerals; Gates, W. P.; Kloprogge, J. T.; Madejova, J.; Bergaya, F., Eds.; Elsevier: Amsterdam, 2017; Vol.' 8, pp 107-149. (37) Madejova, J. FTIR techniques in clay mineral studies.' Vib. Spectrosc. 2003, 31, 1-10. (38) Petit, S.; Baron, F.; Decarreau, A. Synthesis of nontronite and other Fe-rich smectites: a critical review. Clay Miner. 2017, 52, 469- 483.

(39) Philippe, A.; Baravian, C.; Bezuglyy, V.; Angilella, J.; Meneau, F.; Bihannic, I.; Michot, L. Rheological study of two-dimensional very anisometric colloidal particle suspensions: from shear-induced orientation to viscous dissipation. Langmuir 2013, 29, 5315-5324.

(40) Suquet, H.; Pezerat, H. Parameters influencing layer stacking types in saponite and vermiculite: A review. Clays Clay Miner. 1987, 35, 353-362.

(41) Chemeda, Y. C.; Christidis, G. E.; Khan, N. T.; Koutsopoulou, E.; Hatzistamou, V.; Kelessidis, V. C. Rheological properties of palygorskite-bentonite and sepiolite-bentonite mixed clay suspensions. Appl. Clay Sci. 2014, 90, 165-174.

(42) Soomro, F. A.; Usman, M.; Haq, R. U.; Wang, W. Melting heat transfer analysis of Sisko fluid over a moving surface with nonlinear thermal radiation via collocation method. Int. J. Heat Mass Transfer 2018, 126, 1034-1042.

(43) Rashidi, M.; Bagheri, S.; Momoniat, E.; Freidoonimehr, N. Entropy analysis of convective MHD flow of third grade nonNewtonian fluid over a stretching sheet. Ain Shams Eng. J. 2017, 8, 77-85. (44) Low, P. Interparticle forces in clay suspensions: flocculation, viscous flow and swelling. In Clay Water Interface and its Rheological Implications; Güven, N.; Pollastro, R. M., Eds.; CMS Workshop Lectures: Boulder, 1992; Vol. 4, pp 157-190.

(45) Barnes, H. A.; Hutton, J. F.; Walters, K. F. R. S. Chapter 2- Vicosity. In An Introduction to Rheology; Barnes, H. A.; Hutton, J. F.; Walters, K. F. R. S., Eds.; Elsevier: Netherlands, 1993; Vol. 3, pp 11-36.

(46) Liu, R.; Ding, Z.; Hu, K. Stabilities in plane Poiseuille flow of Herschel-Bulkley fluid. J. Non-Newtonian Fluid Mech. 2018, 251, 132-144.

(47) Jeong, S. W.; Locat, J.; Torrance, J. K.; Leroueil, S. Thixotropic and anti-thixotropic behaviors of fine-grained soils in various flocculated systems. Eng. Geol. 2015, 196, 119-125. (48) Gao, B.; Wang, X.-M.; Zhao, X.-Y.; Ding, X.; Fu, X.-X.; Zhang, Y.-L.; He, Q.-F.; Zhang, Z.; Liu, T.-Y.; Huang, Z.-Z.; Chen, L. G.; Peng, Y.; Guo, H. Source apportionment of atmospheric PAHs and their toxicity using PMF: impact of gas/particle partitioning. Atmos. Environ. 2015, 103, 114-120. 
640 (49) Zhang, X.; Xu, J.; Lang, C.; Qiao, S.; An, G.; Fan, X.; Zhao, L.; Hou, C.; Liu, J.

641 Enzyme-regulated fast self-healing of a pillararenebased hydrogel. Biomacromolecules 2017, 18, $642 \quad 1885-1892$.

643 (50) Zamora-Mora, V.; Fernandez-Gutie' rrez, M.; San Roma' n, J.; Goya, G.; Hernandez, R.;

644 Mijangos, C. Magnetic core' - shell chitosan nanoparticles: Rheological characterization and 645 hyperthermia application. Carbohydr. Polym. 2014, 102, 691-698.

646 (51) Kajiya, T.; Daerr, A.; Narita, T.; Royon, L.; Lequeux, F.; Limat,L. Advancing liquid contact 647 line on visco-elastic gel substrates: stickslip vs. continuous motions. Soft Matter 2013, 9 , 648 454-461.

649 (52) Le Goff, K. J.; Gaillard, C.; Helbert, W.; Garnier, C.; Aubry, T. Rheological study of 650 reinforcement of agarose hydrogels by cellulose nanowhiskers. Carbohydr. Polym. 2015, 116, $651 \quad 117-123$.

652 (53) Hasan, A.; Fatehi, P. Cationic kraft lignin-acrylamide copolymer as a flocculant for clay 653 suspensions:(2) Charge density effect. Sep. Purif. Technol. 2019, 210, 963-972.

654 (54) Kunz, W.; Nostro, P. L.; Ninham, B. W. The present state of affairs with Hofmeister effects. 655 Curr. Opin. Colloid Interface Sci. 2004, 9, 1-18.

656 (55) Gong, Y.; Tian, R.; Li, H. Coupling effects of surface charges, adsorbed counterions and 657 particle-size distribution on soil water infiltration and transport. Eur. J. Soil Sci. 2018, 69, $658 \quad 1008-1017$.

659 (56) Del Gaudio, V.; Luo, Y.; Wang, Y.; Wasowski, J. Using ambient noise to characterise seismic 660 slope response: The case of Qiaozhuang peri-urban hillslopes (Sichuan, China). Eng. Geol. 2018, $661246,374-390$.

662 
Table 1. Composition, $\zeta$-Potential, and Average Size of Sap, and Transparency of Sap Sol or Hydrogels

sample $^{a}$ theoretical molar ratio of Si/Mg/Al theoretical LCD actual molar ratio of Si/Mg/Al actual LCD ${ }^{b} \quad \zeta(\mathrm{mV})$ average size $(\mathrm{nm}) \quad$ transparency

$\begin{array}{llllllll}\text { Sap } & 6.6: 6.0: 1.3 & 1.33 & 6.0: 6.0: 1.2 & 1.33 & -46.2 & 502 & \text { opaque } \\ \text { Sap }_{10} & 7.3: 6.0: 0.7 & 0.73 & 6.4: 6.0: 0.7 & 0.74 & -44.6 & 171 & \text { transparent } \\ \text { Sap }_{15} & 7.6: 6.0: 0.5 & 0.50 & 6.5: 6.0: 0.5 & 0.53 & -40.8 & 148 & \text { transparent } \\ \text { Sap }_{20} & 7.6: 6.0: 0.4 & 0.38 & 6.7: 6.0: 0.4 & 0.42 & -39.7 & 245 & \text { transparent }\end{array}$

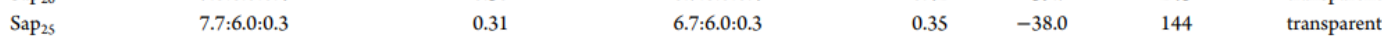

${ }^{a} \mathrm{Sap}_{x}$ indicates the Sap synthesized at the $\mathrm{Si} / \mathrm{Al}$ molar ratio of $x .{ }^{b}$ Data calculated according to the XRF analysis of Sap. In this work, the general formula of Sap can be written as $(\mathrm{Na}, \mathrm{Mg})_{x}\left[\mathrm{Mg}_{6}\right]\left[\mathrm{Si}_{8-x} \mathrm{Al}_{x}\right] \mathrm{O}_{20}(\mathrm{OH})_{4} \cdot n \mathrm{H}_{2} \mathrm{O}$ with a charge $x$ of $1.33-0.35$ per $\mathrm{O}_{20}(\mathrm{OH})_{4} \cdot{ }^{\circ} \mathrm{The}$ transparency of these Sap samples is shown in Figure S1a(I). LCD: Layer charge density (e/per formula unit); $\zeta$ : zeta-potential.

a

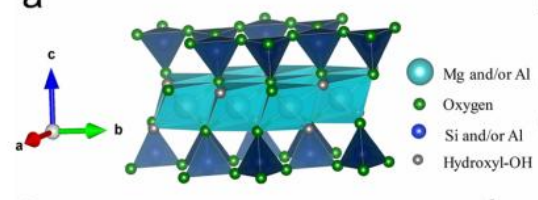

b
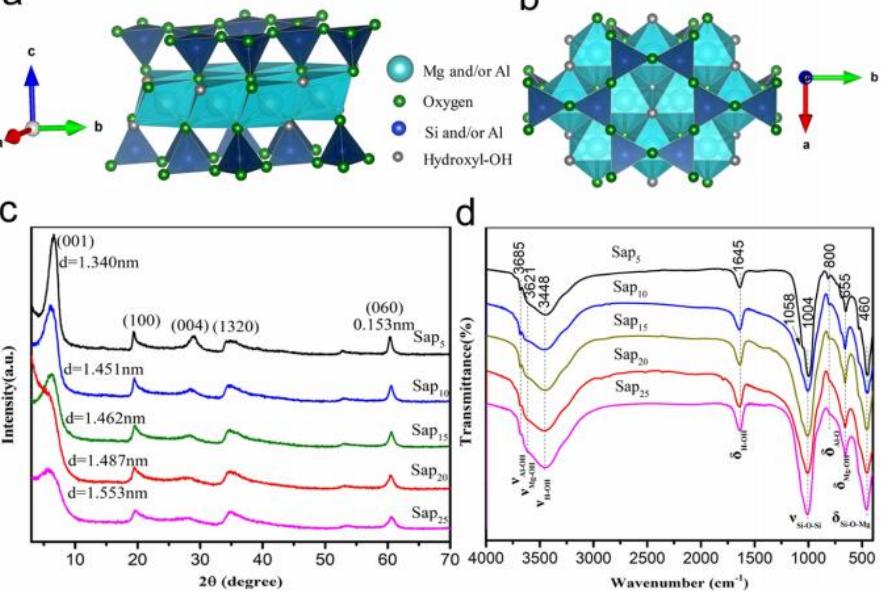

Figure 1. Crystal structure of Sap: (a) two tetrahedral sheets on each side of an octahedral sheet occupied by magnesium and/or aluminum cations, forming two-dimensional (2D) layers; (b) top view of Sap with trioctahedral. (c) Powder XRD patterns and (d) FTIR spectra of Sap sap $_{x}$ 

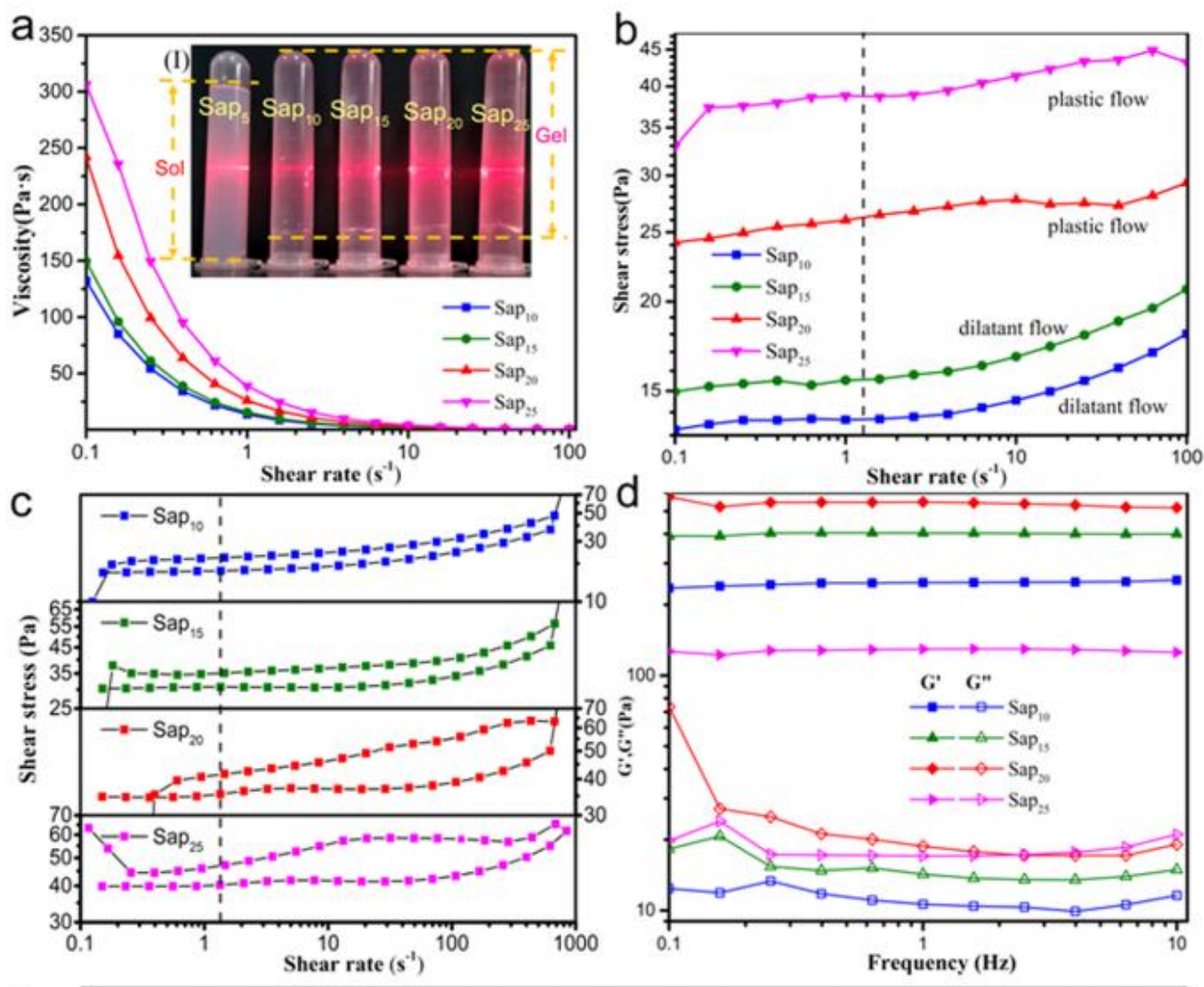

670

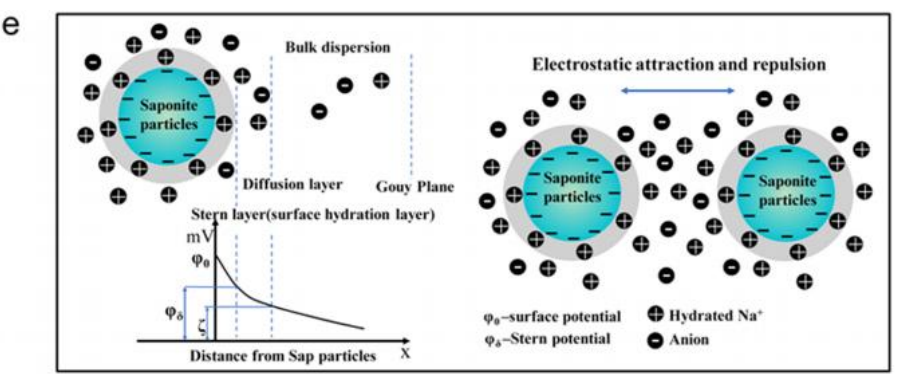

Figure 2. (a) Viscosity as a function of shear rate for Sap $x$ hydrogels. (b) Shear stress as a function of shear rate for Sap f $_{x}$ hydrogels (in the log-log mode). (c) Thixotropic loops as a function of shear rate for Sap $x$ hydrogels (in the log-log mode). (d) Storage modulus ( $\left.G^{\prime}\right)$ and loss modulus $\left(G^{\prime \prime}\right)$ of Sap $x$ hydrogels (in the log-log mode). Schematic drawing of the dispersion mechanism for Sap particles: (e) $\zeta$-Potential of Sap and electrostatic force between Sap particles. The inset (I) in (a): the Tyndall effect (red laser beam) of Sap hydrogels. Sap $_{x}$ means the Sap synthesized 

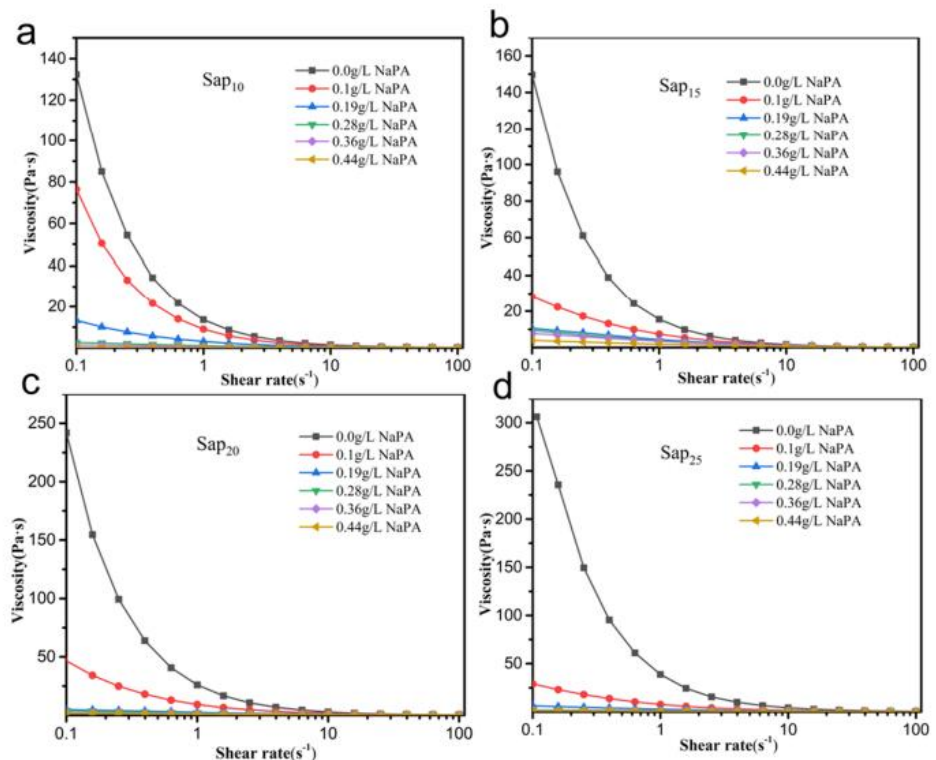

Figure 3. Viscosity as a function of shear rate (shear rate in the log mode) for (a) $\mathrm{Sap}_{10}-\mathrm{NaPA}_{y}$, (b) $\mathrm{Sap}_{15}-\mathrm{NaPA}_{y}$, (c) $\mathrm{Sap}_{20}-\mathrm{NaPA}_{y}$ and (d) $\mathrm{Sap}_{25}$ NaPA dispersions, where $y$ means the addition of NaPA from 0.1 to $0.44 \mathrm{~g} / \mathrm{L}$ of aqueous Sap dispersion.
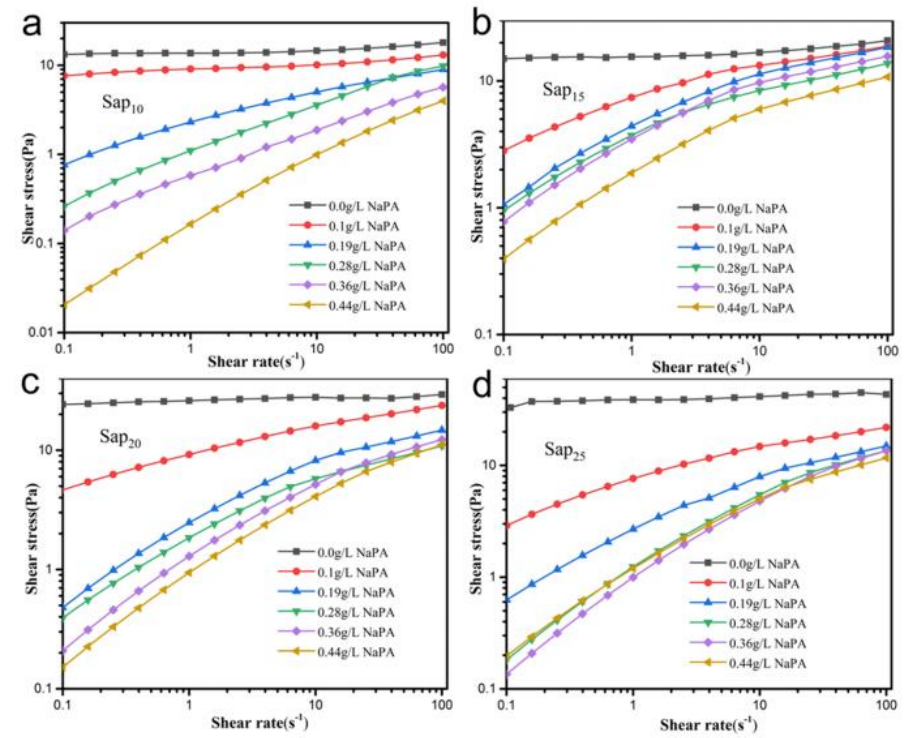

Figure 4. Shear stress as a function of shear rate for (a) $\mathrm{Sap}_{10}-\mathrm{NaPA}_{y}$, (b) Sap $15-\mathrm{NaPA}_{y}$, (c) $\mathrm{Sap}_{20}-\mathrm{NaPA}_{y}$, and (d) $\mathrm{Sap}_{25}-\mathrm{NaPA}_{y}$ dispersions (in the 676 

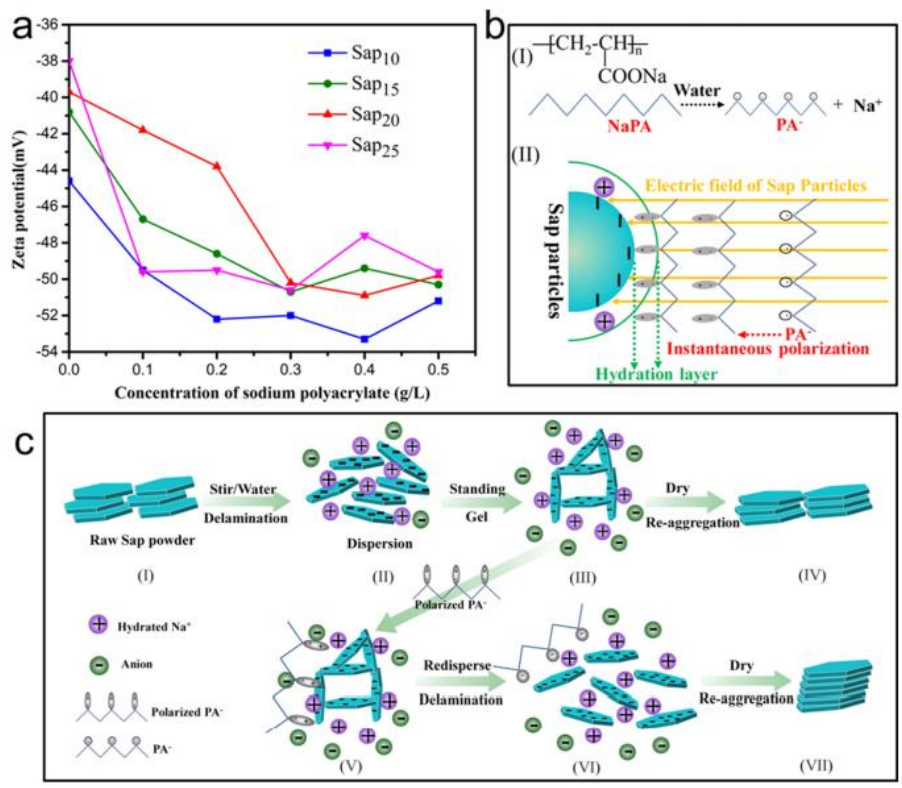

Figure 5. (a) $\zeta$-Potential of Sap dispersion as a function of sodium polyacrylate (NaPA) concentration. (b) Illustrations of the interactions between Sap particles and sodium polyacrylate (NaPA): (I) Chemical formula of NaPA and schematic structure of NaPA; (II) interaction between aggregated Sap particle and NaPA. (c) Schematic illustration of Sap dispersion with/without added NaPA and reaggregation after drying: (I) Sap dispersed in water to form (II) Sap dispersion and (III) Sap hydrogel; (V) interaction of the Sap hydrogel with polarized PA to form (VI) Sap-
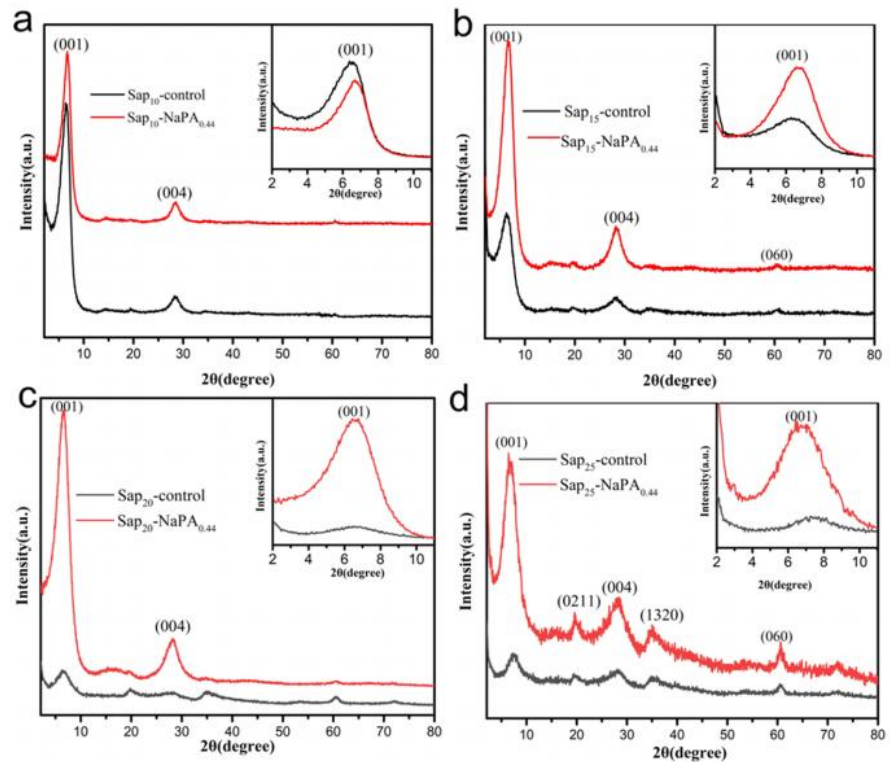


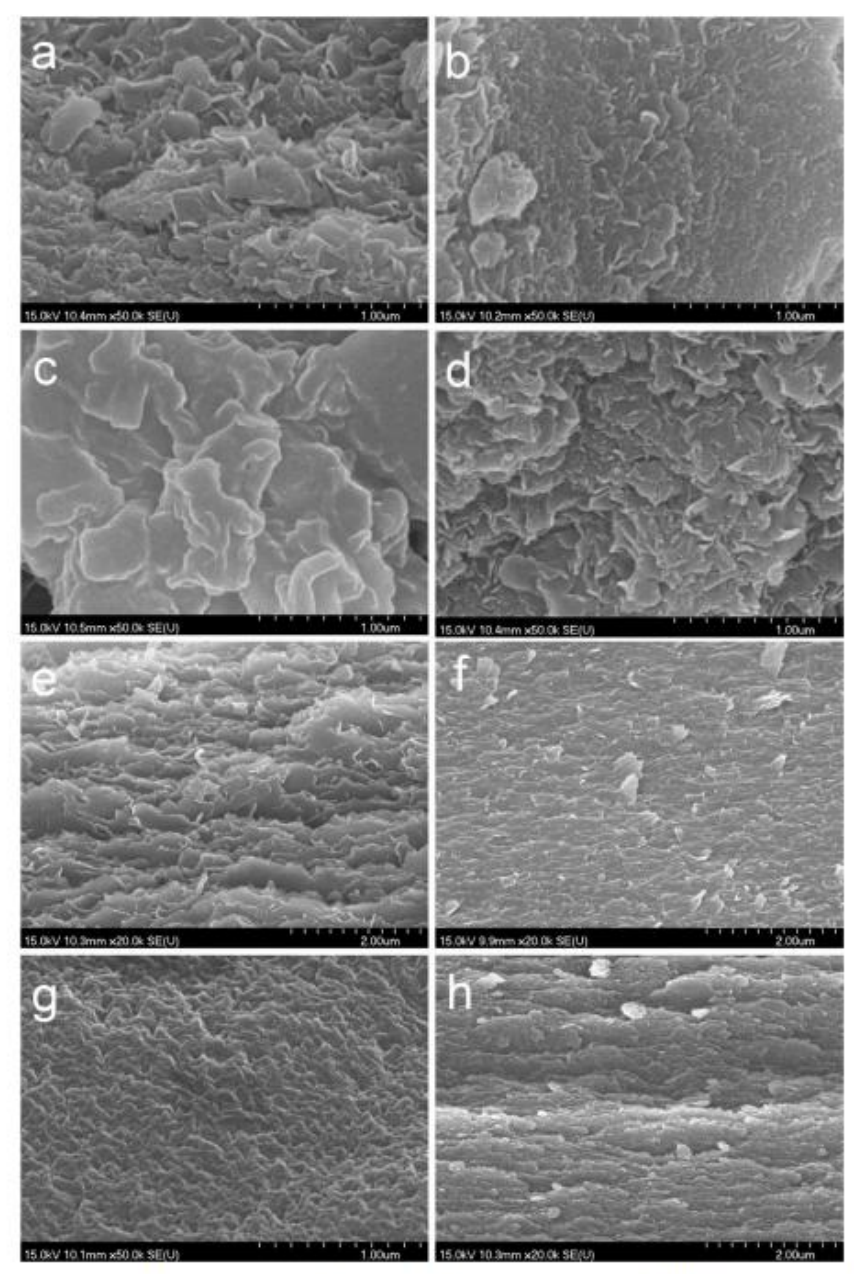

Figure 7. SEM images of (a) $\mathrm{Sap}_{10}$ (b) $\mathrm{Sap}_{15}$ (c) $\mathrm{Sap}_{20}$ (d) $\mathrm{Sap}_{2,5}$ (e) $\mathrm{Sap}_{10}-\mathrm{NaPA}_{0,40}$ (f) $\mathrm{Sap}_{15}-\mathrm{NaPA}_{0,40}$ (g) $\mathrm{Sap}_{20}-\mathrm{NaPA}_{0,4,4}$ and (h) $\mathrm{Sap}_{25}$ $\mathrm{NaPA}_{0.44} \mathrm{Sap}_{x}-\mathrm{NaPA}_{0.44}$ dried from Sap dispersion after adding NaPA at the concentration of $0.44 \mathrm{~g} / \mathrm{L}$. 